\title{
EHMTI-0360. Chronic sympathetic activation in migraine headache: unique to migraine or common to sympathetic nervous system disorders?
}

\author{
MR Thomas \\ From 4th European Headache and Migraine Trust International Congress: EHMTIC 2014 \\ Copenhagen, Denmark. 18-21 September 2014
}

The mechanisms of autonomic nervous system dysfunction in migraine are not well understood. It has been proposed that chronic/excessive SNS activation contributes to migraine episodes by rapidly depleting norepinephrine stores while increasing the release of dopamine, adenosine triphosphate, adenosine and prostaglandins. Research showing significantly colder hands in female migraineurs than healthy controls between headaches suggests evidence of chronic/excessive SNS activation in female migraineurs.

A recent audit of standardized clinical assessment data collected over several years during a 26 minute psychophysiological mental stress assessment revealed interesting results which shed light on this dilemma. Data included hand skin temperature (HST), frontal sEMG, HR, SCR, respiration rate and the Anxiety Sensitivity Index. Ten female migraineurs (MH), 10 females with muscle contraction headache $(\mathrm{MCH})$ and 10 females with panic disorder (PD) were compared.

$\mathrm{MCH}$ controlled for the effects of having a distressing non-migraine/non SNS headache disorder. PD controlled for the effects of having a distressing non-headache, SNS disorder.

There were no significant between-group differences for age and most test scores.

A repeated measures ANOVA showed a significant between-groups difference for HST. The MCH group was in the normal range while the $\mathrm{MH}$ and PD groups were well below normal and significantly colder than the $\mathrm{MCH}$ group.

The MH group results suggest chronic SNS arousal. However the PD group's similar result and the $\mathrm{MCH}$ normal result suggests that chronic SNS arousal is a characteristic of SNS disorders and is not unique to migraine. Alone, it appears insufficient to explain migraine episodes. Additional factors are proposed.

No conflict of interest.

Published: 18 September 2014

doi:10.1186/1129-2377-15-S1-J12

Cite this article as: Thomas: EHMTI-0360. Chronic sympathetic activation in migraine headache: unique to migraine or common to sympathetic nervous system disorders? The Journal of Headache and Pain 2014 15(Suppl 1):J12.

Clinical Psychology, Private Practice, Whitby, Canada

Submit your manuscript to a SpringerOpen ${ }^{\circ}$ journal and benefit from:

- Convenient online submission

- Rigorous peer review

- Immediate publication on acceptance

- Open access: articles freely available online

- High visibility within the field

- Retaining the copyright to your article

Submit your next manuscript at $\boldsymbol{~ s p r i n g e r o p e n . c o m ~}$

\section{SpringerOpen ${ }^{\circ}$}

(C) 2014 Thomas; licensee Springer. This is an Open Access article distributed under the terms of the Creative Commons Attribution License (http://creativecommons.org/licenses/by/2.0), which permits unrestricted use, distribution, and reproduction in any medium, provided the original work is properly cited. 